\title{
Statins reduce hepatic Angpt13 expression and secretion, likely by interfering with LXR-mediated transcription
}

\author{
Aldo Grefhorst ${ }^{1}$, Laurens F. Reeskamp², Roeland Huijgen², G. Kees Hovingh²
}

${ }^{1}$ Experimental Vascular Medicine and ${ }^{2}$ Vascular Medicine, Amsterdam University Medical Centers - location AMC, Amsterdam, The Netherlands

\section{Introduction}

Loss of function mutations in ANGPTL3 cause low plasma lipid concentrations.

Statins supposedly suppress hepatic ANGPTL3 mRNA expression in healthy subjects ${ }^{1}$, but the mechanism is unknown.

It is also not known whether statins reduce plasma Angptl3 concentrations in patients with elevated LDLC, e.g., familial hypercholesterolemia (FH).

1. J. Intern. Med. 2011: 269: 333

\section{Methods}

Plasma Angptl3 concentrations were measured in 157 genetically confirmed FH patients and in 129 age and sex matched unaffected relatives.

The effect of simvastatin on ANGPTL3 mRNA expression and Angptl3 secretion was assessed in the human hepatoma cell line Huh7.

Contact: a.grefhorst@amsterdamumc.nl

\section{Results}

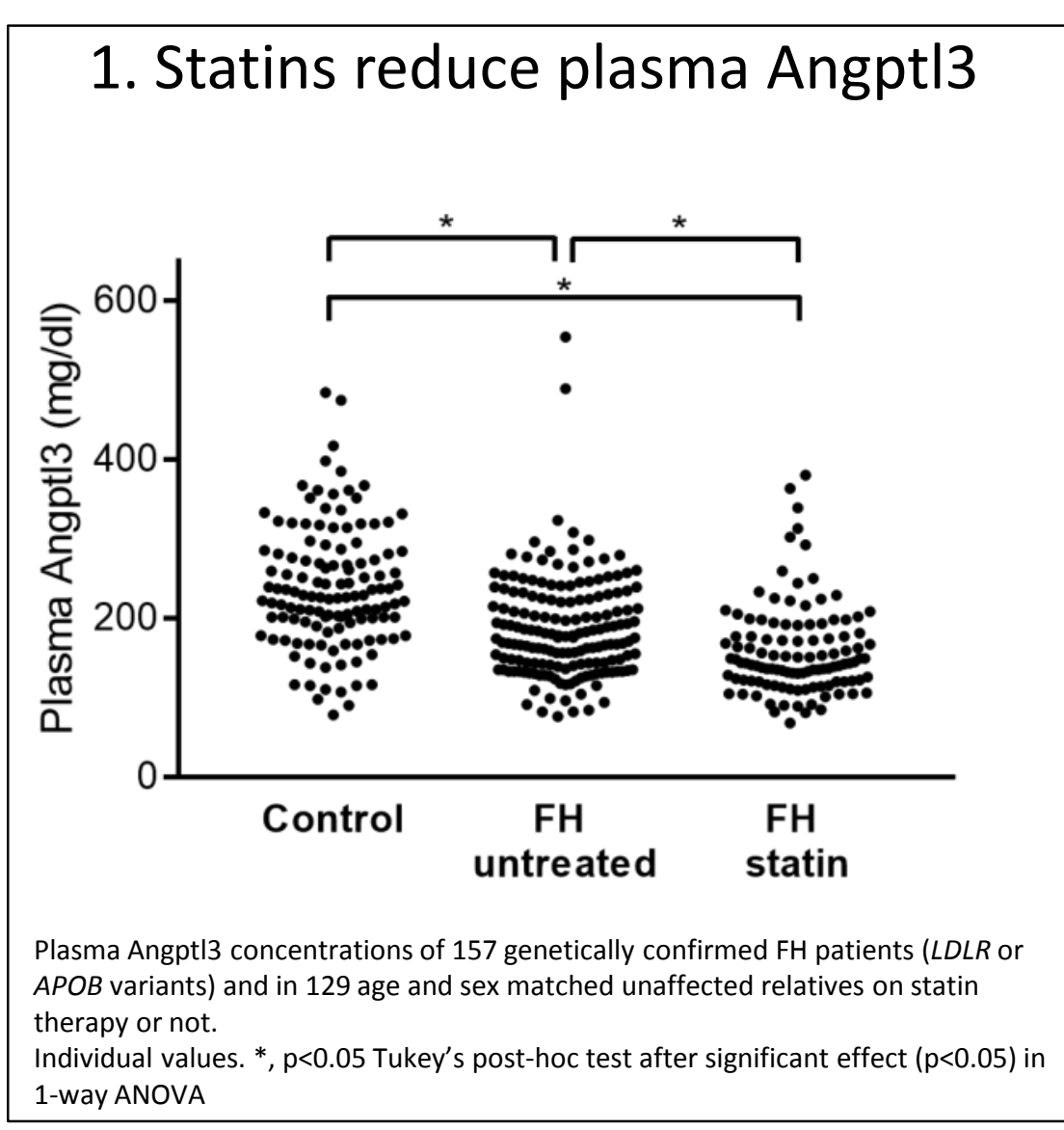

3. Lower LXR target gene expression upon simvastatin treatment

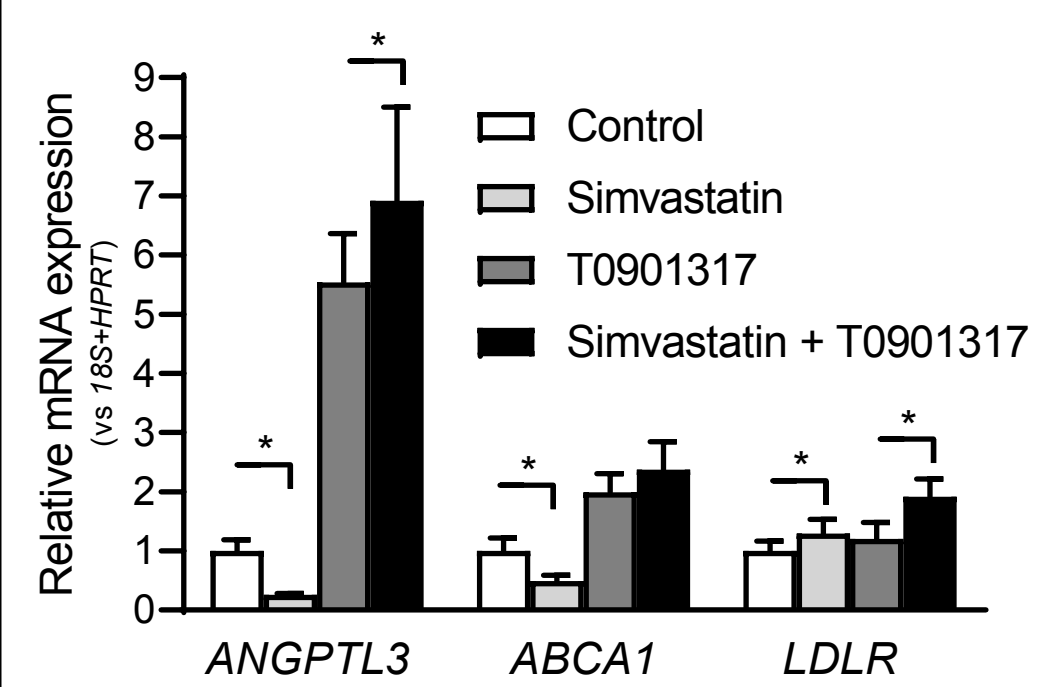

Relative mRNA expression of Huh7 cells treated $2.5 \mu \mathrm{M}$ simvastatin and/or $1 \mu \mathrm{M}$ T0901317 for $24 \mathrm{~h}$

Averages + - SEM, $n=8 .{ }^{*}, p<0.05$ vs. no simvastatin, same T0901317 concentration (Student's T-test).
2. Simvastatin decreases ANGPTL3 mRNA expression and Angpt/3 secretion but not when LXR is activated

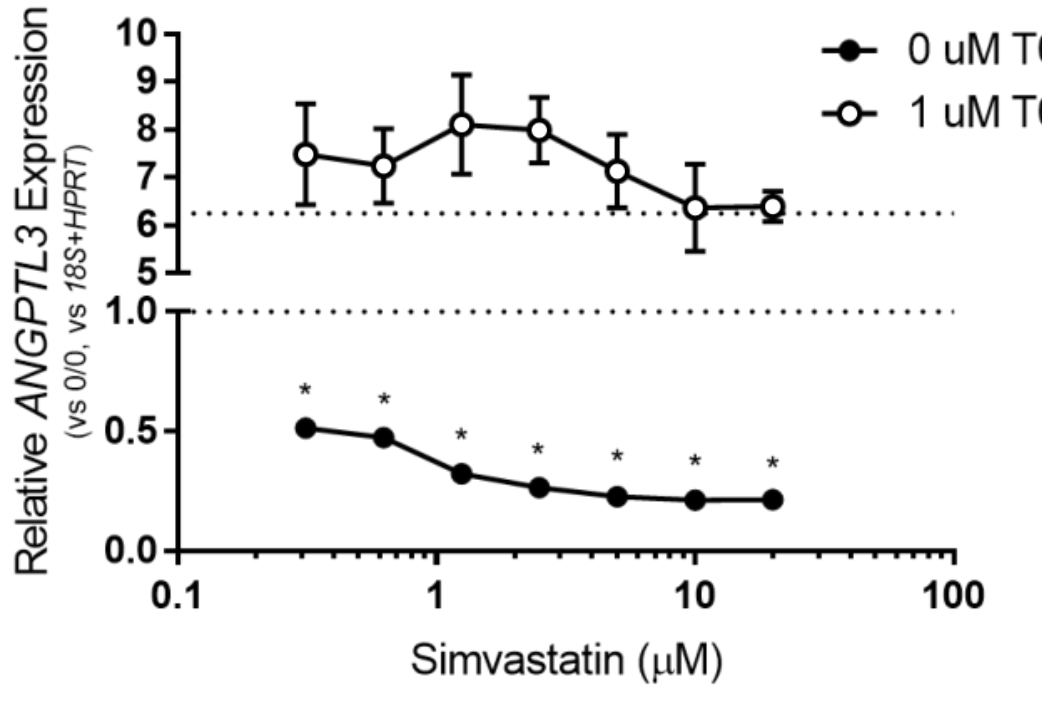

Relative ANGPTL3 mRNA expression of Huh7 cells treated with indicated simvastatin concentrations for 24 hith They's post-hoc test after significant effect $(p<0.05)$ in 1-way ANOVA.

4. The LXR antagonist GSK2033 prevents reductions in Angptl3 by simvastatin
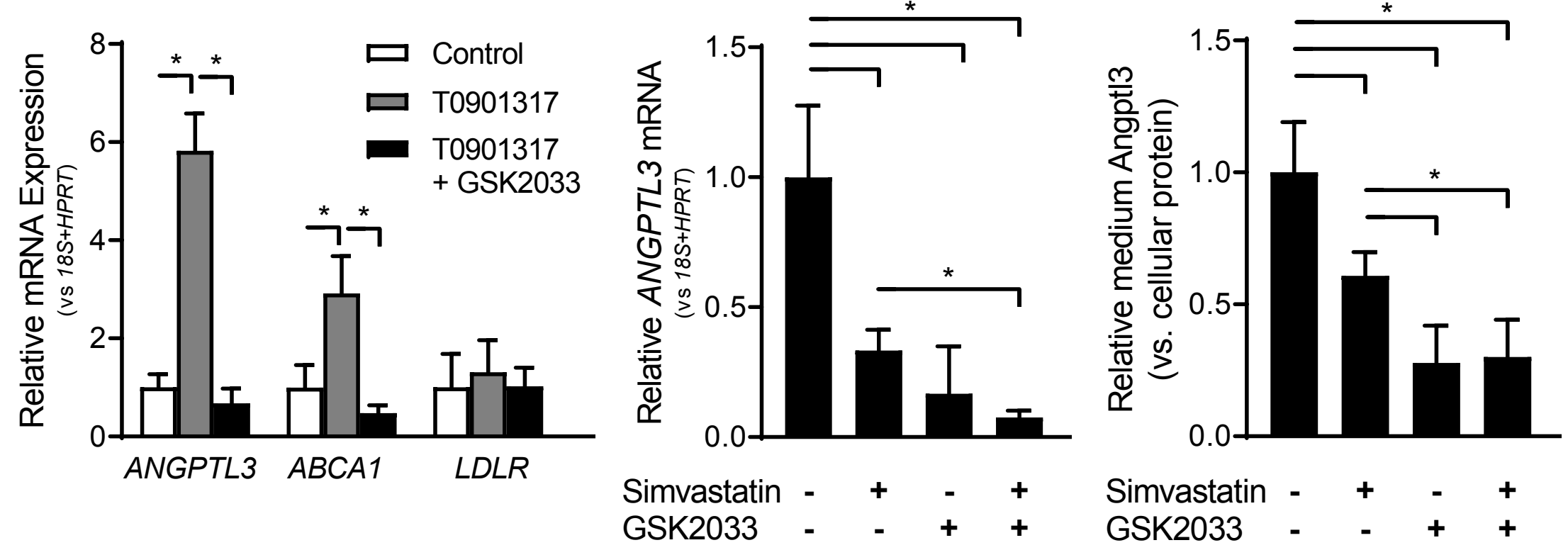

Simvastatin - + - + GSK2033 - - + +

Relative mRNA expression of Huh7 cells treated with $1 \mu \mathrm{M}$ T0901317 with/without $10 \mu \mathrm{M}$ GSK2033 for $24 \mathrm{~h}$. Averages + - - SEM, $n=8$.*. $p<0.05$ Tukey's post-hoc test after significant effect $(p<0.05)$ in 1-way ANOVA.

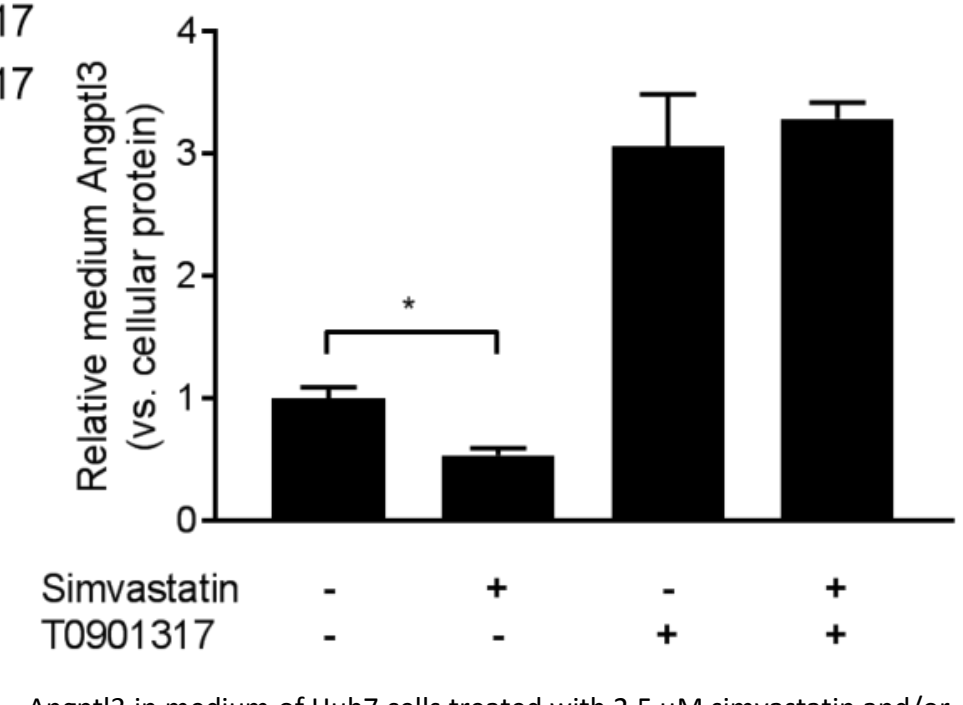

Angpt13 in medium of Huh7 cells treated with $2.5 \mu \mathrm{M}$ simvastatin and/or $1 \mu \mathrm{M}$ T0901317 for $24 \mathrm{~h}$. concentration (Student's
Relative ANGPTL3 mRNA expression (left) and Angpt|3 in the medium (right) of Huh7 cells treated with $2.5 \mu \mathrm{M}$ simvastatin and/or $10 \mu \mathrm{M}$ GSK2033 for $24 \mathrm{~h}$ Averages +/- SEM, $n=3-6 . *, p<0.05$ Tukey's post-hoc test after significant effect $(p<0.05)$ in 1-way

\section{Conclusion}

Statins reduce hepatic ANGPTL3 mRNA expression and plasma Angpt13 concentrations by interfering with the effect of LXR on ANGPTL3 transcription. This is likely due to a reduction of the endogenous LXR ligands, oxysterols. 